\title{
Implementasi Pose To Pose Pada Simulasi Gerak Panda Berjalan Dengan Teknik Frame By Frame
}

Ibnu Hadi Purwanto 1), Laila Qodarsih 2), Fatimah Hafizh Majid 3), Khalida Arlinta Syamrahmarini 4) Universitas Amikom Yogyakarta

ibnu@amikom.ac.id ${ }^{1}$

\begin{abstract}
Abstrak
Perkembangan animasi saat ini semakin memberi tuntutan bagi para animator untuk menyelesaikan pekerjaannya dengan cepat. Di bab ini akan membahas tentang metode yang mana akan mempermudah animator untuk menyelesaikan produksi animasi tanpa membuang-buang waktu. Membuat simulasi gerakan Panda berjalan dengan membandingkan antara pose to pose dan tanpa pose to pose.

Animasi 2D yang dipengaruhi oleh proses animating yang baik pada gerakannya akan menjadikan animasi terlihat lebih hidup. Teknik pose to pose adalah salah satu metode yang digunakan pada proses animating karena pada penerapan metode ini menggunakan perinsip-prinsip dasar animasi. Penggunaaan metode frame by frame biasanya digunakan pada membuatan object yang sangat detail dan halus. Metode ini biasa dikatakan dengan metode animasi tradisional.

Dengan penggunaan pose to pose dan tanpa pose to pose akan diketahui perbedaan pergerakan panda berjalan yang dihasilan. Perbandingan yang dilakukan bertujuan untuk mengetahui manakah yang menghasilkan proses lebih cepat dan baik dalam pengerjaannya.
\end{abstract}

Kata kunci: Animasi, metode, frame by frame, pose to pose

\section{Pendahuluan}

\section{a. Latar Belakang}

Semakin berkembangnya teknologi saat ini didunia industri animasi. Salah satu proses yang penting dalam produksi sebuah animasi adalah proses animating. Dalam proses ini sangat dibutuhkan untuk menciptakan gerak animasi yang terlihat nyata.

Dengan kata lain jika animasi terlihat tidak nyata atau kaku akan dianggap tidak menarik. Untuk menghasilkan gerak animasi yang baik sangat perlu memahami prinsip-prinsip dan metode yang digunakan dalam proses animating.

Salah satu metodenya adalah pose to pose yaitu dengan membuat beberapa pose penting yang mewakili suatu gerak animasi, dan dilanjutkan dengan pose yang menghasilkan efek gerak animasi itu sendiri.

Dalam hal ini, implementasi pose to pose akan diterapkan pada simulasi gerak panda yang berjalan dan membandingkan juga bila pembuatanya tanpa pose to pose (frame by frame).

\section{b. Rumus Masalah}

Berdasarkan dari hasil latar belakang yang telah disampaikan diatas, maka rumusan masalah dalam implementasi pose to pose pada gerakan Panda dan dalam penggunaan tanpa pose to pose (frame by frame) adalah :
1. Bagaimana penerapan pose to pose pada simulasi gerak panda?

2. Bagaimana perbandingan dari animasi yang menggunakan pose to pose dan tanpa pose to pose?

c. Kajian Pustaka

Imam Styawan STMIK Amikom

Yogyakarta Merancang Animasi 2D Pick Nick dengan Menggunakan Metode Frame by Frame Hand Drawn Animation, pada pembuatan animasi Pick Nick menggunakan 2 tahap yang dibuat dengan pensil dan tahap kedua dengan cara tracking. Dalam proses ini gambar yang dibuat dipisahkan cut per cut adegan sehingga akan terpisah gambar yang berupa frame yang terdiri dari layer per cut nya [4].

\section{Multimedia}

Multimedia berasal dari kata multi dan media. Multi berasal dari bahasa latin, yaitu nouns yang berarti banyak. Sedangkan media berasal dari bahasa latin, yaitu medium yang berarti perantara atau suatu yang dipakai untuk menyampaikan, menghantarkan, atau membawa sesuatu.

Menurut Reddi (2003) mengartikan multimedia yaitu suatu intergrasi elemen berupa media (audio, video, grafik, teks, animasi dII) menjadi sebuah kesatuan yang sinergis dan simbiosis yang memberikan hasil yang lebih 
menguntungkan bagi pengguna dari pada elemen media secara individual [5].

Jadi pengertian mulitimedia adalah menyajikan dan menggabungkan teks, suara, gambar, animasi, audio dan video dengan alat bantu (tool) dan koneksi (link) sehingga pengguna dapat melakukan navigasi, berinteraksi, berkarya dan berkomunikasi. Multimedia sering digunakan dalam dunia informatika. Selain dari dunia informatika, Multimedia juga diadopsi oleh dunia game, dan juga untuk membuat website.

\section{Animasi}

Menurut Reiber (1994) bagian penting pada multimedia adalah animasi. Animasi berasal dari bahasa latin yaitu "anima" yang berarti jiwa, hidup, semangat. Secara umum animasi merupakan suatu kegiatan menghidupkan, atau megerakan benda mati. Animasi terbagi menjadi dua jenis yaitu, animasi 2D dan animasi 3D.

Animasi 2D berupa jenis animasi yang lebih dikenal dengan film kartun yang pembuatannya menggunakan teknik animasi hand draw atau animasi sel, penggambaran langsung pada film atau secara digital. Didalam animasi terdapat karakter, karakter adalah orang, hewan maupun objek nyata lainnya yang dituangkan dalam bentuk gambar. Sehingga karakter animasi dapat diartikan sebagai gambar yang memuat objek yang seolah-olah hidup, disebabkan oleh kumpulan gambar itu berubah beraturan dan bergantian ditampilkan. Objek dalam gambar bisa berupa tulisan, bentuk benda, warna dan spesial efek.

Dalam pembuatan animasi terdapat teknik yang digunakan seperti, cut to cut, stop motion, frame by frame dan masih banyak lagi. Frame by frame merupakan teknik animasi yang disusun dari banyak rangkaian gambar yang berbeda. Pada teknik ini, setiap perubahan gerak atau bentuk objek diletakkan pada frame secara berurutan. Semakin banyaknya frame, animasi yang dihasilkan akan semakin halus [5].

\section{12 Prinsip Animasi 2D}

Menurut BINUS University School Of Design [1] prinsip animasi terdiri dari 12 prinsip yaitu :

a. Squash And Stretch

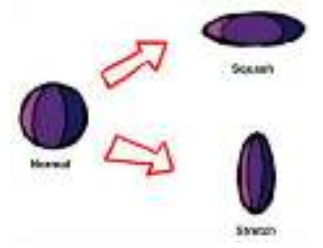

Gambar 1. Squash And Stretch

b. Anticipation

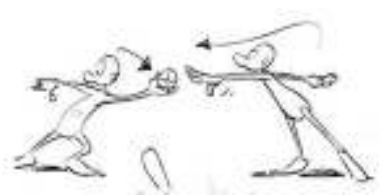

Gambar 2. Anticipation

c. Staging

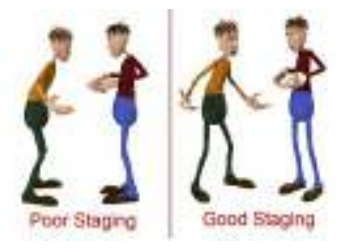

Gambar 3. Staging

d. Follow Through And Overlapping
Action

e. Slow In And Slow Out

f. Arcs

g. Secondary Action

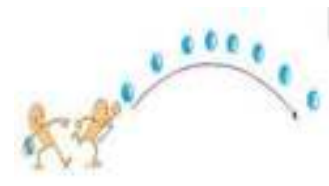

Gambar 4. Secondary Action

h. Timing

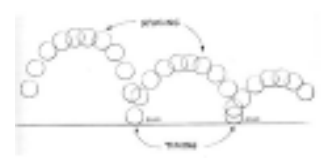

Gambar 5. Timing 
j.Solid Drawing

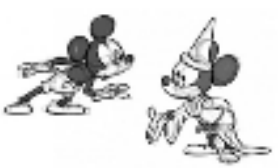

\section{k. Appeal}

Gambar 6. Solid Drawing

1. Straight Ahead Action \& Pose To Pose Straight ahead adalah pengambaran satu persatu pergerakan dari awal sampai selesai.

Pose to pose adalah berisi gambaran-gambaran keyframe tertentu, selanjutnya untuk meembuat gerakan antara satu pose ke pose lainnya dengan memberikan inbetween agar gerakan terlihat lebih detail.

\section{Pembahasan}

\section{a. Pra-Produksi}

Di tahap pra produksi semua kebutuhan disiapkan dan disesuaikan dengan proyek yang di kerjakan. Dalam proyek ini kebutuhan yang diperlukan yaitu, ide karakter. Tahap ini membuat sketsa karakter panda yang digambar dikertas dengan pensil.

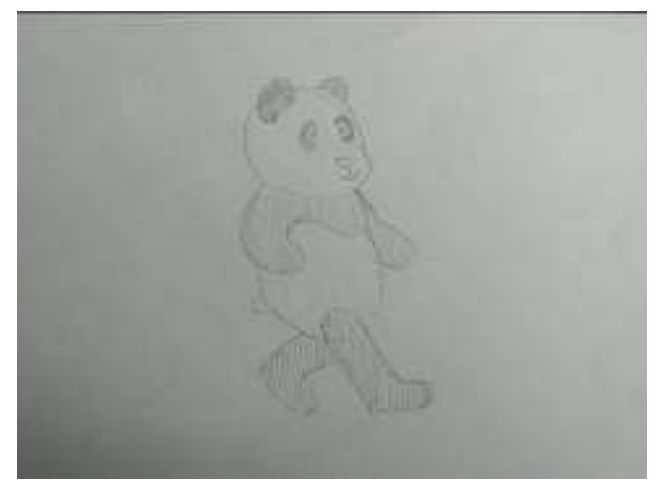

Gambar 7. Sketsa Panda

\section{b. Produksi}

Pada tahap ini, karakter yang telah di konsepkan akan masuk pada tahap penerapan prinsip pose to pose. Penerapan pose to pose ini digunakan mengatur gerakan. Animasi yang dikerjakan pada tahap ini adalah dengan menentukan gerakan keyframe, ekstreme, dan inbetween. Untuk mengatur keyframe diperlukan pengaturan frame yang baik. Semakin banyak frame yang digunakan akan menghasilkan gerakan yang lambat, sebaliknya semakin sedikit frame yang digunakan akan menghasilkan gerakan yang cepat.
Setelah menentukan keyframe, selanjutnya menentukan gerakan tambahan yang berada di antara keyframe yang lebih memperhalus animasi agar terlihat lebih alami dan tidak kaku yang disebut dengan inbetween.

a) Langkah-langkah penerapan animasi pose to pose pada Adobe Flash CS6

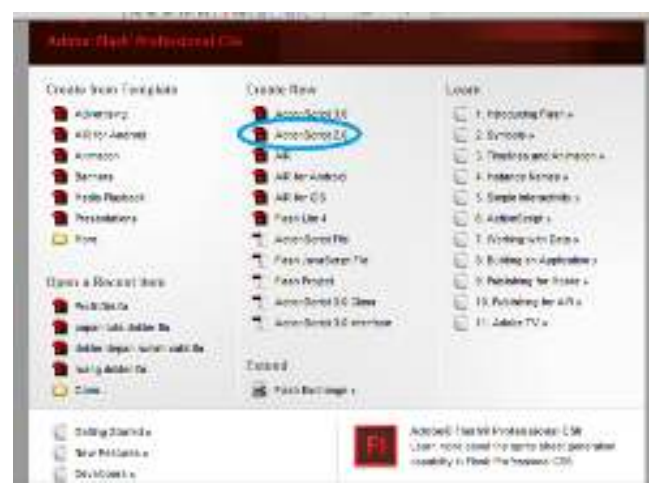

Gambar 8. Penentuan action script

Pada gambar 8, tampilan awal ketika membuka adobe flash CS6, pilih action script 2.0 untuk membuat projek baru.

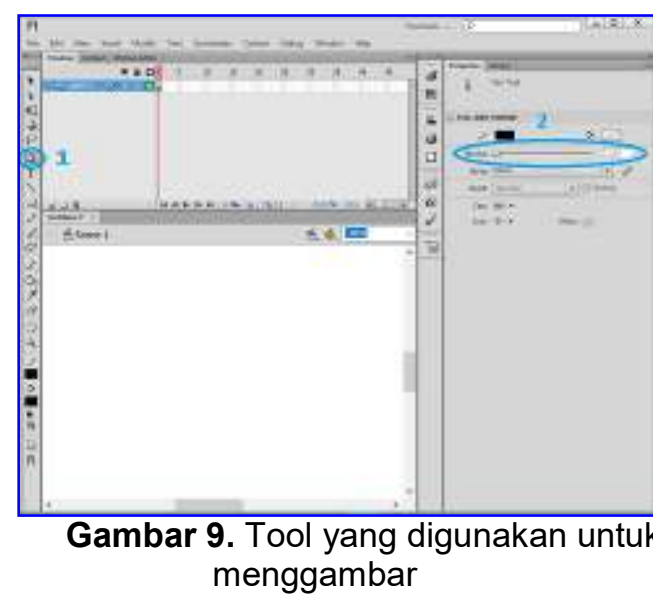

Pada gambar 9, pilihlah pen tool yang terdapat pada panel tools dan sesuaikan size garis menjadi 1,00 pada stroke.

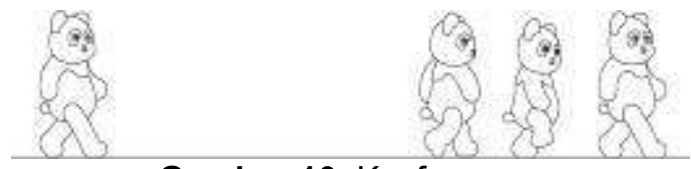

Gambar 10. Keyframe

Pada gambar 10, menentukan keyframe untuk menunjukkan gerakan animasi awal.

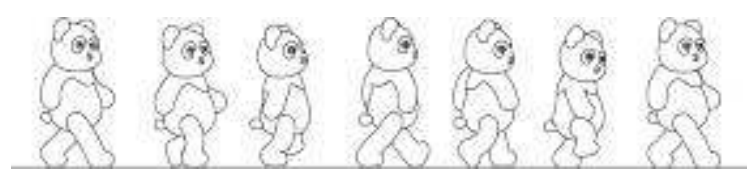

Gambar 11. Extreme 
Pada gambar 11, setelah menentukan keyframe, selanjutnya menentukan extreme. Extreme adalah serangkaian pose yang dibuat untuk menunjukkan efek gerak animasi, meskipun hasil gerak animasi belum sepenuhnya sempurna.

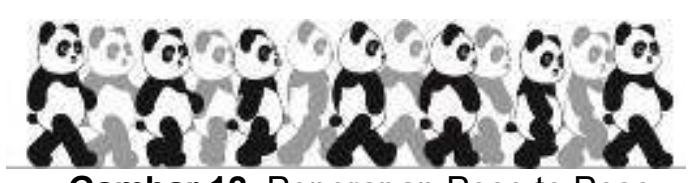

Gambar 12. Penerapan Pose to Pose

Pada gambar 12, langkah selanjutnya memperhalus gerakan animasi dengan memberikan inbetween diantara extreme yang sudah dibuat seperti pada Gambar 11. Jadi yang dihasilkan terdapat 9 frame. Untuk memperjelas gambar panda, tambahkan warna hitam dibagian tubuh.

b)Langkah-langkah penerapan animasi tanpa pose to pose pada Adobe Flash CS6
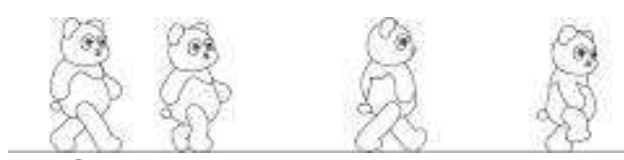

Gambar 13. Tanpa penerapan pose to pose

Pada gambar 13, menunjukkan gerakan key saja dengan jumlah 5 frame pada pergerakan panda, tanpa adanya pose to pose pergerakkan panda menjadi kaku dan tidak natural.

\section{Kesimpulan}

Berdasarkan penelitian tentang penggunaan metode pose to pose pada simulasi gerak panda berjalan maka kesimpulan yang didapatkan pada penelitian ini yaitu:

1)Dalam metode pose to pose yang diterapkan pada simulasi panda berjalan ini menghasilkan gerakan yang memiliki kualitas pergerakkan pada animasi ini terlihat realis.

2) Hasil perbandingan dari animasi yang menggunakan pose to pose dan tanpa pose to pose dapat dilihat dari jumlah framenya. Dengan menggunakan pose to pose frame yang digunakan sebanyak 9 frame, sedangkan tanpa pose to pose hanya menggunakan 5 frame. Jadi dapat disimpulkan semakin banyak frame yang digunakan maka gerakan akan semakin realis.

3)Untuk mengasilkan sebuah animasi 2 dimensi yang baik harus melalui beberapa tahapan kerja yaitu keyframe, inbetween, extreme dan coloring.

\section{Daftar Pustaka}

BINUS University School Of Design, 2010, 12 Prinsip Animasi, Bandung.

Eko Purwanto, 2004, Demo Membuat Animasi Teori dan Praktek, IlmuKomputer.com.

Erika D. Indraswari, 2012, Kiat Belajar Gerak Karakter Animasi, Jurnal Humaniora, Vol. 3, No. 2.

Imam Styawan, 2013, Merancang Animasi 2D Pick Nick dengan Metode Frame by Frame Hand Drawn Animation Penelitian Skripsi Edisi 2013, STMIK Amikom Yogyakarta

Munir, 2012, Multimedia Konsep \& Aplikasi dalam Pendidikan, Bandung : Alfabeta.

Puspasani, 2013, Pembuatan Film kartun 2 Dimensi "Runo, The Green Cartepillar Menggunakan Teknik Straight Ahead and Pose to Pose", Yogyakarta: ANDI.

Rona Guines Purnasiswi, 2013, Perancangan dan Pembuatan Animasi 2D "Kerusakan Lingkungan" dengan Teknik Masking, STMIK Amikom Yogyakarta.

Subektinigsih, 2012, Pembuatan Film Animasi 2 Dimensi "Zebra Wannabe" Menggunakan Teknik Tweening Animation Penelitian Skipsi Edisi 2012, STMIK Amikom Yogyakarta.

Victor Waeo, 2016, Implementasi Gerakan Manusia pada Animasi 3D dengan Menggunakan Metode Pose to Pose, Jurnal Teknik Informatika, Vol. 9, No. 1. 